\title{
Clinical Application of Ambient Ionization Mass Spectrometry
}

\author{
Li-Hua Li" ${ }^{\#, 1}$, Hua-Yi Hsieh ${ }^{\#, 2}$, and Cheng-Chih Hsu*,2 \\ ${ }^{1}$ Department of Pathology and Laboratory Medicine, Taipei Veterans General Hospital, Taipei, Taiwan \\ ${ }^{2}$ Department of Chemistry, National Taiwan University, Taipei, Taiwan
}

\begin{abstract}
Ambient ionization allows mass spectrometry analysis directly on the sample surface under atmospheric pressure with almost zero sample pretreatment. Since the development of desorption electrospray ionization (DESI) in 2004, many other ambient ionization techniques were developed. Due to their simplicity and low operation cost, rapid and on-site clinical mass spectrometry analysis becomes real. In this review, we will highlight some of the most widely used ambient ionization mass spectrometry approaches and their applications in clinical study.
\end{abstract}

Copyright (c) 2017 Li-Hua Li, Hua-Yi Hsieh, and Cheng-Chih Hsu. This is an open access article distributed under the terms of Creative Commons Attribution License, which permits use, distribution, and reproduction in any medium, provided the original work is properly cited and is not used for commercial purposes.

Please cite this article as: Mass Spectrom (Tokyo) 2017; 6(2): S0060

Keywords: ambient ionization, clinical mass spectrometry, point-of-care-test

(Received October 17, 2016; Accepted January 7, 2017)

\section{INTRODUCTION}

Mass spectrometry (MS) has become a powerful and wide-range technique in analytical and bioanalytical chemistry. In most of the mass spectrometry analysis, the samples are usually gone through procedures such as purification and separation before introduced into mass spectrometers. ${ }^{1)}$ Over the last few decades, efforts have been made to improve the detection sensitivity for biological samples and complex mixtures. Separation procedures like liquid chromatography are usually implemented for such purpose. Meanwhile, a great amount of time and resources are required during these procedures. In the context of analysis that must take high-throughput results, for example a thousand clinical samples per day, the chromatography, e.g., gas chromatography (GC) and liquid chromatography (LC), before the mass spectrometry interrogation becomes impractical. In the past decade, an alternative strategy known as ambient ionization mass spectrometry (AIMS) was developed and aiming for a rapid MS detection at much lower $\operatorname{cost}^{2-4)}$ (Fig. 1).

AIMS is generally referred to as any ionization methods performed under the open-air condition for the subsequent MS analysis directly on the sample surface with almost zero sample pretreatment. ${ }^{5)}$ The concept of ambient ionization and sampling prior to mass spectrometric analysis was first introduced with the invention of desorption electrospray ionization (DESI) and direct analysis in real time (DART) in 2004 and 2005, respectively. ${ }^{5,6)}$ Since then, numerous related or derived ambient ionization techniques were developed.
Due to their simplicity and low operation cost, clinical uses such as cancer diagnosis are proposed and becoming possible by using AIMS. ${ }^{7)}$ In this review, we will highlight some of the most widely used AIMS modules and their applications in clinical realm (Table 1).

\section{DESORPTION ELECTROSPRAY IONIZATION (DESI)}

Instead of a laser beam or a primary ion beam as the ionization sources, DESI generates ions by spraying a stream of solvent droplets with the pneumatic assistance of a nitrogen gas flow (Fig. 2). The pneumatically-assisted primary droplets contact the sample surface, and subsequently extract and mobilize analytes away from it. Consequently, charged secondary droplets are formed and transported to mass spectrometer through an inlet capillary. ${ }^{8)}$ Although its mechanism is not fully understood, the MS property of DESI is similar to that of electrospray ionization (ESI). In common DESI-MS results, protonated species or $\mathrm{Na}^{+} / \mathrm{K}^{+}$ adducts are found in the positive ion mode and deprotonated species are found in the negative ion mode. The solvent system chosen for DESI is crucial to the result of measurements. In most of the DESI-MS experiment, water, methanol, acetonitrile, dichloromethane and their mixtures are often used as the spray solvents. ${ }^{9)}$ The extraction efficiency greatly depends on the polarity of solvents. In fact, finding an appropriate solvent system is important to obtain the optimal signal readouts for different classification of target molecules. One of the key parameters of DESI is the solvent spray angle. The incident angle is about 45 to 55 degree (the

\footnotetext{
*Correspondence to: Cheng-Chih Hsu, Department of Chemistry, National Taiwan University, Taipei, Taiwan, e-mail: ccrhsu@ntu.edu.tw
}

\# These authors contributed equally to this work. 


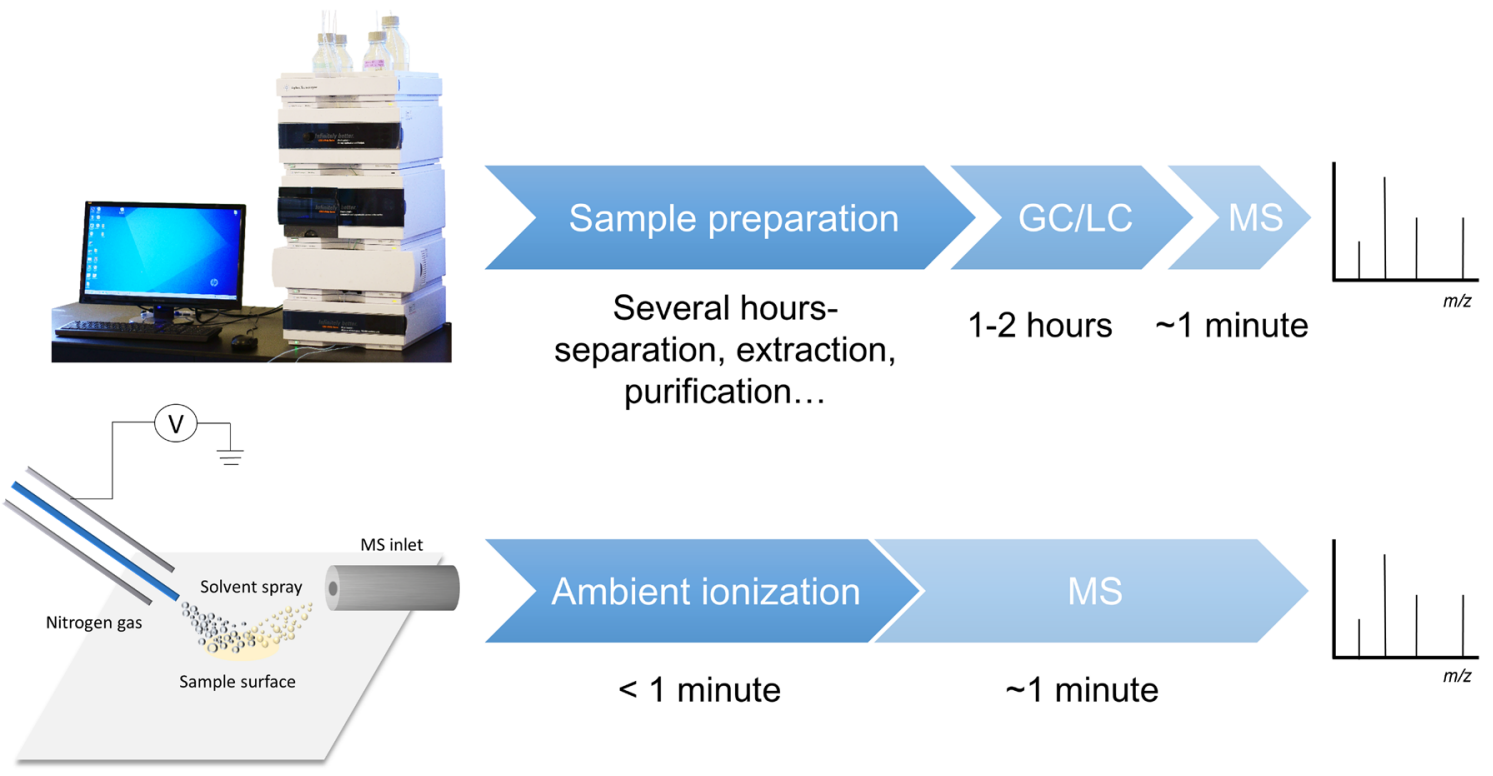

Fig. 1. Ambient ionization mass spectrometry versus conventional LC/GC-MS.

angle between the primary spray and the sample plane) in many DESI-MS study. ${ }^{10-12)}$

DESI can be operated in 2-dimensional (2D) mode on the sample surface for mass spectrometry imaging (MSI). Through moving the sample stage to make the solvent spray scan across the sample surface, position-dependent MS profiles are obtained and can be reconstructed into MS image. ${ }^{13-15)}$ Three-dimensional profile can also be established by aligned multiple 2D DESI-MS spectra. ${ }^{16)}$ The typical spatial resolution of DESI is about $200 \mu \mathrm{m}$ whereas a $35-\mu \mathrm{m}$ resolution was reported with the modification of the solvent-capillary and sampling geometry. ${ }^{17)}$

\section{Clinical applications of DESI-MS}

Dried blood spot (DBS) is a common form of sampling and storage for its convenience and small carrier sample volume. Mass spectrometry-based analysis has been implemented for point of care-testing (POCT) on DBS. ${ }^{1)}$ For example, DESI-MS has been successfully applied to DBS analysis and has shown a good quantitative evaluation for the level of drugs like sitamaquine, terfenadine, and prazosin. ${ }^{18)}$ Reactive DESI is a variant of DESI and found useful in the clinical applications. Reagents are adopted to react with specific classification of compounds in analytes by forming bonds or adducts. The greatest advantage of reactive DESI is the possibility of detecting molecules which are difficult to be ionized in traditional ESI-MS. The specific reactivity of the reagent to the target significantly helps to increase the selectivity and sensitivity of target compounds. Target compounds such as cis-diol, ${ }^{19)}$ hydroxyl-containing molecules, ${ }^{10)}$ and lipids ${ }^{20)}$ have been reported.

Numerous works about using DESI to identify cancerous tissues have been reported, including breast cancer, ${ }^{21)}$ prostate cancer, ${ }^{22)}$ and brain cancer. ${ }^{23,24)}$ Most of these works focus on the altered profiles of the lipid composition to classify the cancerous sections. One of the reasons is that the remarkable difference of lipid profiles does exist in cancerous cell. Yet another reason is that lipids are easily ionized by DESI and become dominant species. Though it has been applied to numerous cases of tissue imaging, DESI is not ap- plicable to in vivo tissue analysis because the surface flatness is critical to the quality of ion signal and the number of the ions introduced into the mass spectrometer inlet is sensitive to the distance between the sample surface and the ion inlet.

\section{NANOSPRAY DESORPTION ELECTROSPRAY IONIZATION (nanoDESI) AND LIQUID MI- CROJUNCTION SURFACE SAMPLING PROBE (LMJ-SSP)}

Despite its name, nanoDESI is not a nanospray version of "DESI" but rather based on continuous liquid flow microjunction surface sampling ${ }^{25)}$ (Fig. 2). Instead of solvent spray in DESI, nanoDESI uses a micrometer droplet generated between two capillaries to mobilize analytes from the sample surface. After the solvent dissolves and extracts analytes from the surface, the analytes are then transported to the mass spectrometer inlet through the secondary capillary. A high voltage about $2-5 \mathrm{kV}$ should be applied between the primary capillary and the mass spectrometer. A better spatial resolution is provided by minimizing the inner diameter of the capillary and controlling the flow rate to reduce the contact area. Meanwhile, the spatial resolution of nanoDESI is comparable with DESI in most of the studies. ${ }^{25,26)}$

LMJ-SSP has a close sampling procedure to nanoDESI, but a dual coaxial tube in LMJ-SSP replaces the capillary junction in nanoDESI as the sampling probe. Similarly, a solvent bridge between the analysis surface and the probe extracts compounds from the sample. A Venturi pump coupling to the ESI source is used to pull the sample extracts from the surface for subsequent ionization before MS measurement. ${ }^{27)}$ Because of the similarity in mechanism, nanoDESI and LMJ-SSP have similar MS features. Both of the techniques can conduct MS imaging. In addition, a technique, which is similar to LMJ-SSP, called single-probe mass spectrometry was reported and it provides an improved spatial resolution $(\sim 8.5 \mu \mathrm{m})$ to LMJ-SSP. ${ }^{28)}$

\section{Clinical applications of NanoDESI and LMJ-SSP}

NanoDESI and LMJ-SSP have the ability to extract and 
Table 1. Clinical applications of ambient ionization mass spectrometry (AIMS).

\begin{tabular}{|c|c|c|c|c|c|}
\hline Technique & Year & Type of sample & Application & Molecular Species $^{\mathrm{a}}$ & Reference \\
\hline \multirow[t]{6}{*}{ DESI } & 2009 & $\begin{array}{l}\text { Human serum, rat brain } \\
\text { section }\end{array}$ & $\begin{array}{l}\text { Hydroxyl-containing } \\
\text { molecules detection }\end{array}$ & $\begin{array}{l}\text { Cholesterol, glucose, fructose, } \\
\text { phospholipids }\end{array}$ & 10 \\
\hline & 2010 & Human blood & Therapeutic drug monitoring & $\begin{array}{l}\text { Sitamaquine, prazosin, } \\
\text { terfenadine, verapamil }\end{array}$ & 18 \\
\hline & 2012 & Brain tissue section & Brain cancer diagnosis & PS, PI, FA & 24 \\
\hline & 2014 & Breast tissue section & Breast cancer diagnosis & FA, PI, PS, PE & 21 \\
\hline & 2014 & Brain tissue section & Brain cancer diagnosis & 2-Hydroxyglutarate & 33 \\
\hline & 2015 & Prostate tissue section & Prostate cancer diagnosis & PE, PS, PC, PI & $22^{\mathrm{b}}$ \\
\hline \multirow[t]{2}{*}{ LMJ-SSP } & 2008 & Rat tissue & $\begin{array}{l}\text { Drug and metabolites } \\
\text { detection }\end{array}$ & $\begin{array}{l}\text { Reserpine, glutathione, } \\
\text { sulforaphane }\end{array}$ & 27 \\
\hline & 2013 & Sheep blood & $\begin{array}{l}\text { Protein identification, drug } \\
\text { detection }\end{array}$ & $\begin{array}{l}\text { Hemoglobin, hydroxypro- } \\
\text { pranolol, hydrochloride }\end{array}$ & 29 \\
\hline \multirow[t]{2}{*}{ NanoDESI } & 2013 & Mouse tissue section & $\begin{array}{l}\text { Proteins and peptides } \\
\text { identification }\end{array}$ & $\begin{array}{l}\text { Hemoglobin, ubiquitin, PC, } \\
\text { glutathione, }\end{array}$ & 30,31 \\
\hline & 2016 & Skin tissue & Psoriasis diagnosis & $\begin{array}{l}\text { Choline, glutamic acid, canic } \\
\text { acid, citrulline }\end{array}$ & 32 \\
\hline \multirow[t]{2}{*}{ DART } & 2013 & Human serum & $\begin{array}{l}\text { Metabolic fingerprinting } \\
\text { screening }\end{array}$ & Not assigned & 35 \\
\hline & 2015 & Human plasma & Metabolite quantification & Tyrosine & 36 \\
\hline \multirow[t]{4}{*}{ REIMS } & 2010 & Human tissue & Tissue types identification & Phospholipids & 44 \\
\hline & 2013 & Human tissue & Tissue types identification & PA, PE, PI & 41 \\
\hline & 2015 & $\begin{array}{l}\text { Human tissue, bacterial } \\
\text { growth media }\end{array}$ & $\begin{array}{l}\text { Tissue and bacteria } \\
\text { identification }\end{array}$ & PA, PG, PI, PE, PQS & 43 \\
\hline & 2015 & Porcine tissue, human tissue & Tissue (polyp) identification & TG, PI, PE & 45 \\
\hline \multirow[t]{3}{*}{$\begin{array}{l}\text { Touch spray ioniza- } \\
\text { tion }\end{array}$} & 2014 & $\begin{array}{l}\text { Human blood, human } \\
\text { prostate, mouse brain }\end{array}$ & $\begin{array}{l}\text { Therapeutic drug monitoring, } \\
\text { cancer diagnosis }\end{array}$ & $\begin{array}{l}\text { MDMA, methamphetamine, } \\
\text { cocaine, PC, PS, PI, FA }\end{array}$ & 55 \\
\hline & 2014 & Throat swab & $\begin{array}{l}\text { Strep throat-related bacterium } \\
\text { identification }\end{array}$ & PG & 56 \\
\hline & 2015 & Prostate tissue & Prostate cancer diagnosis & PE, PS, PC, PI & $22^{\mathrm{b}}$ \\
\hline \multirow[t]{3}{*}{ Probe-ESI } & 2013 & Rat liver & $\begin{array}{l}\text { Cancer diagnosis } \\
\text { (hepatocellular carcinoma) }\end{array}$ & PC, TAG & 58 \\
\hline & 2013 & $\begin{array}{l}\text { Human urine, oral fluid, } \\
\text { plasma }\end{array}$ & Illicit drug monitoring & $\begin{array}{l}\text { Methamphetamine, } \\
\text { morphine, cocaine, codeine }\end{array}$ & 57 \\
\hline & 2011 & $\begin{array}{l}\text { Human kidney, porcine } \\
\text { kidney, stomach }\end{array}$ & Kidney cancer diagnosis & PI, PE, PS & 59 \\
\hline \multirow{4}{*}{$\begin{array}{l}\text { Paper spray } \\
\text { ionization }\end{array}$} & 2010 & Human blood, urine & Therapeutic drug monitoring & Imatinib, heroine, atenolol & 66 \\
\hline & 2011 & Human blood & Therapeutic drug monitoring & Propranolol, atenolol & 76 \\
\hline & 2012 & Human blood, serum & Newborn screening & Acylcarnitines & 67 \\
\hline & $2011-2016$ & $\begin{array}{l}\text { Bovine whole blood, rat blood, } \\
\text { human blood }\end{array}$ & $\begin{array}{l}\text { Therapeutic drug monitoring, } \\
\text { protein identification }^{c}\end{array}$ & $\begin{array}{l}\text { Amitriptyline, cotinine, } \\
\text { methamphetamine, } \\
\text { citalopram, hemoglobin }^{\mathrm{c}}\end{array}$ & $\begin{array}{l}69,72^{\mathrm{c}}, 77 \\
82,97\end{array}$ \\
\hline \multirow[t]{2}{*}{ Extractive-ESI } & 2007 & Human skin & Metabolites detection & Nicotine, caffeine & 87 \\
\hline & 2013 & Human breath & Metabolites detection & Acetonitrile & 88 \\
\hline Laser ablation-ESI & 2016 & Bacterial colonies & $\begin{array}{l}\text { Bacterial colonies identifica- } \\
\text { tion }\end{array}$ & $\begin{array}{l}\text { PE, PG, lipids, bacterial } \\
\quad \text { metabolites }\end{array}$ & 91 \\
\hline \multirow[t]{2}{*}{$\begin{array}{l}\text { Thermal } \\
\text { desorption-ESI }\end{array}$} & 2016 & Human oral fluid & Pesticides identification & $\begin{array}{l}\text { Paraquat, methamidophos, } \\
\text { dimethoate, chlorpyrifos, } \\
\text { methomyl, triphenyl, } \\
\text { phosphate }\end{array}$ & 92 \\
\hline & 2016 & Gastric lavage content & Medications identification & $\begin{array}{l}\text { Acetaminophen, diphen- } \\
\text { hydramine, propranolol, } \\
\text { doxepin }\end{array}$ & 94 \\
\hline
\end{tabular}

a Abbreviations in this column: PS, glycerophosphoserines; PI, glycerophosphoinositols; FA, fatty acids; PC, glycerophosphotidylcholines; PE, glycerophosphoethanolamines; PA, phosphatidic acids; PQS, Pseudomonas quorum signal, e.g., 2-heptyl-3-hydroxy-4(1H)-quinolone; PG, phosphatidylglycerols; TG, triglyceride; TAG, triacylglycerol; MDMA, 3,4-methylenedioxymethamphetamine.

${ }^{b}$ TSI- and DESI-MS experiments were both conducted in ref. 22

${ }^{\mathrm{c}}$ Protein identification of hemoglobin was only reported in ref. 72 .

detect proteins from the sample surface. ${ }^{25,29)}$ Cytochrome $c$ in the solution can be ionized and detected by nanoDESI as the form of multiple charge states. ${ }^{25)}$ Two high-abundant proteins in serum, hemoglobin subunits $\alpha$ and $\beta$, were also found with adequate signals in the complex matrix such as dried sheep blood spot utilizing LMJ-SSP technique. ${ }^{29)}$ Two recent reports showed that when interfacing with high resolution mass spectrometry, nanoDESI can be used to resolve
MS signals of proteins and polypeptides directly from the surface of biological sections for the subsequent top-down sequence identification. ${ }^{30,31)}$ Ambient ionization technologies cannot only serve as an ion source independently in analysis, but are also combined with LC system orthogonally. For example, a LMJ-SSP were combined with HPLC and by doing so two isobaric hydroxypropranolol glucuronide metabolites from liver tissue are detected at different reten- 

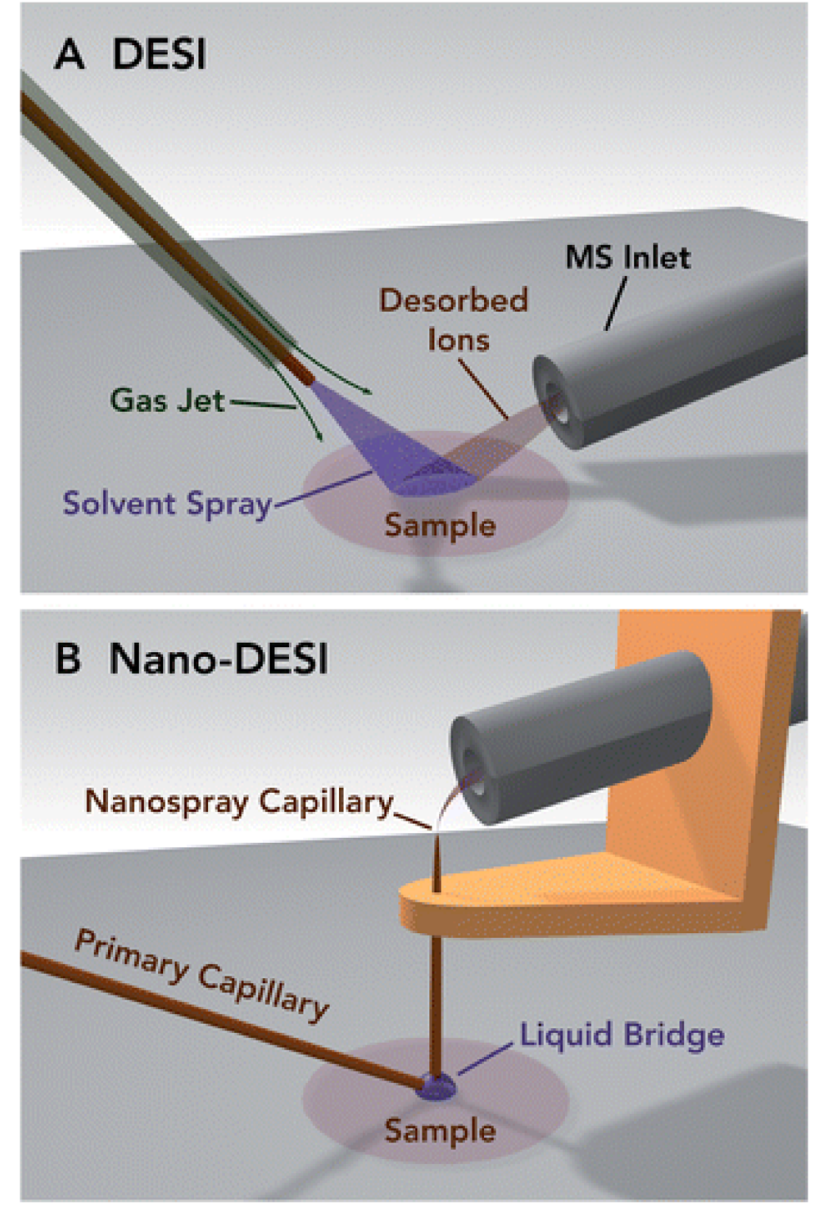

Fig. 2. Desorption electrospray ionization (DESI) and nanospray desorption electrospray ionization (nanoDESI). Figures are reproduced with permission. ${ }^{25)}$

tion time, which is difficult to achieve by using MS alone. ${ }^{29)}$

In terms of POCT, nanoDESI can successfully discriminate excretion molecules from psoriatic skin and healthy skin metabolites, including choline, glutamic acid, canic acid and citrulline. ${ }^{32)}$ The spectral profiles were analyzed through principle component analysis (PCA) and partial least squares-discriminant analysis (PLS-DA), revealing the difference between healthy control and psoriasis patients. The sampling method utilizes a hydrogel micropatch probe to gather metabolites from patients or healthy people. The entire procedure takes only about $15 \mathrm{~min}$, which is crucial for clinical application.

\section{DIRECT ANALYSIS IN REAL TIME (DART)}

Rather than spray-extraction based mechanism of DESI, DART generates ions by utilizing plasma. Therefore, DART technology has similar properties with atmospheric pressure chemical ionization (APCI). ${ }^{12}$ ) Arise from this distinction between DART and DESI, DART forms ions by mechanisms including charge transfer and Penning ionization, ${ }^{33)}$ which are less common for DESI. In DART, an excited helium gas stream is used to generate metastable species, which subsequently react with analytes to form gaseous ions. ${ }^{34)}$ Factors including desorption temperature, discharge energy, gas flow rate and distance between the electrode and the object affect ionization efficiency of DART. ${ }^{35)}$ DART has a greater ability to form ions from non-polar molecules, ${ }^{33)}$ which are more difficult to be ionized in the regular DESI analysis. Usually, the applicable mass range of DART is at 50 to 1,200 $\mathrm{m} / z$.

\section{Clinical applications of DART}

Due to its excellent applicability of variant kinds of molecules, DART has been introduced to the MS interrogation of different samples, including human plasma, ${ }^{36)}$ milk powder, ${ }^{37)}$ and Chinese herbal medicines. ${ }^{38)}$ In the case of human serum, tyrosine is one of the most abundant amino acid in the blood and used as an index of human body health. As reported, tyrosine was successfully detected and quantified accurately utilizing DART. ${ }^{36}$ ) The serum samples do not need any pretreatment before the analysis. In addition to the targeted analysis of specific chemicals, the untargeted screening of human serum was performed. Metabolomic fingerprinting of serum or other body fluids can reflect the status of body health, and also serve as a potential indicator of abnormal conditions or diseases. The temperature of helium gas is revealed as an important factor when scanning such large mass range covering multiplex chemical species. Ion signals in different mass ranges show unequal responses to the temperature adjustment, and thus the temperature of helium gas are usually optimized for molecules of interests. ${ }^{35)}$

Derivatization is an applicable approach to obtain the signals of target compounds to a detectable level in complex mixtures. For example, the report in 2010 by Zhou et al. shows that by applying mono-, di- and tri-methylsilane derivatization, compounds in serum become more volatile and easier to react with precursor ions generated from the DART electrode. ${ }^{39)}$ As a result, there is a 15 -fold increase in signal intensity using this approach. Meanwhile, only analytes reacting with the derivatization reagent have increased intensities. This targeted strategy provides an alternative approach to gain more biochemical information in the MS profiles.

\section{RAPID EVAPORATIVE IONIZATION MASS SPECTROMETRY (REIMS)}

Rapid evaporative ionization mass spectrometry (REIMS) was first published in 2009 by Schäfer et al. ${ }^{40)}$ REIMS generates gaseous molecular ions by thermal evaporation and the ionic species are transferred into mass spectrometer using a Venturi pump remotely. This feature makes REIMS allow real-time intraoperative MS investigation on living objects, such as human patients. An electrosurgical probe is usually used in REIMS. When the electric current emits from the electrode applies to the sample, rapid Joule-heating results in temperature rising and evaporation of the sample. Gaseous charged ions are transferred to the mass spectrometry through a flexible tube. This makes it compatible with other equipment in the operating theatre ${ }^{41)}$ (Fig. 3).

Small molecules are more easily desorbed and turned into gas phase. As a result, REIMS technique has better ionization efficiency for the molecules of $\mathrm{m} / \mathrm{z}$ range below 1000 , and especially suitable for analysis of lipids. ${ }^{42)}$ The spatial resolution of REIMS is about $500-750 \mu \mathrm{m}$ depending on the imaging modes. ${ }^{43)}$ The heating rate, ion generating rate and ion transfer efficiency in the flexible tube influence the sig- 


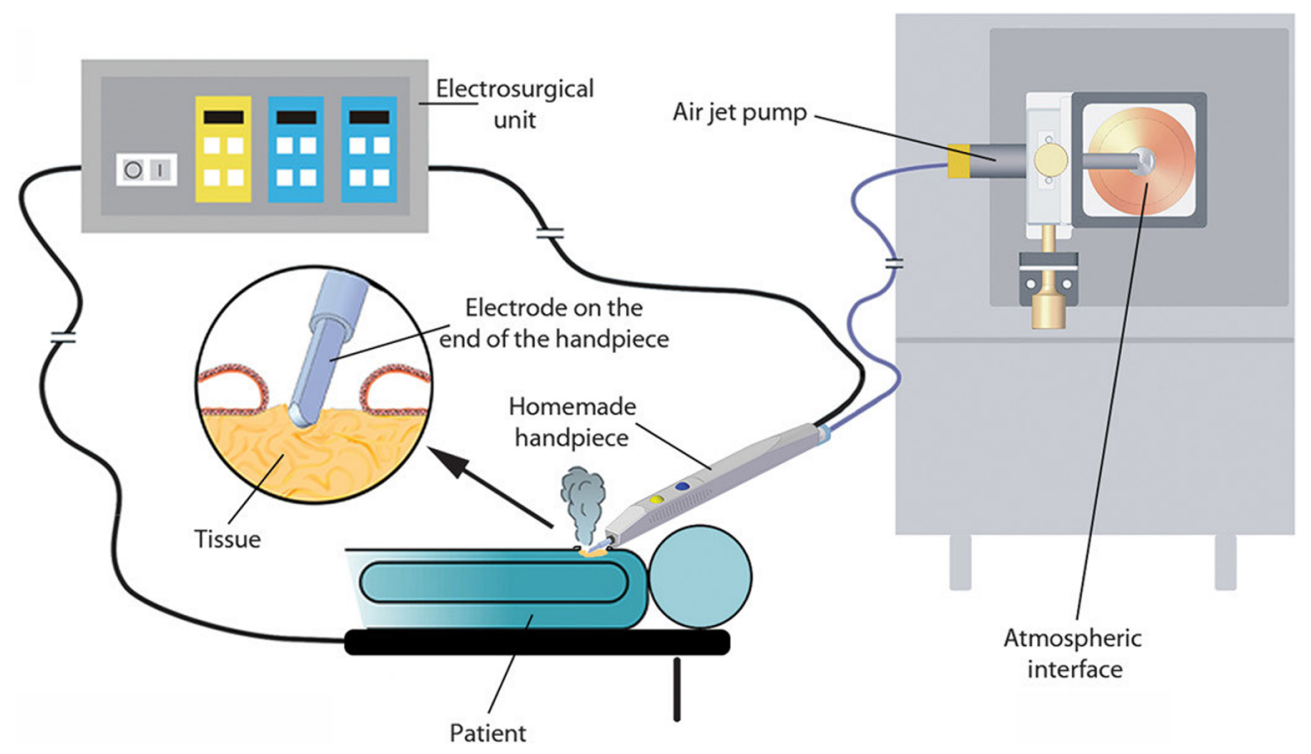

Fig. 3. REIMS instrumentation in surgical application. Figures are reproduced with permission. ${ }^{41)}$

nal stability and the spectral quality. Higher heating power brings to higher evaporation rate and ionization efficiency, but in the same time, higher risky of component dissociation. For example, phosphoethanolamine (PE) degradation, such as loss of ammonia group, may occur when the applied temperature rises. ${ }^{44)}$ REIMS is one of the few AIMS methods which can be conducted in vivo, or operated under online conditions during experiments. ${ }^{7)}$ As a result, the introducing of REIMS to the surgical applications is served by combining mass spectrometry with clinical medicine.

\section{Clinical applications of REIMS}

REIMS provides an almost instantaneous MS profile and the organs/tissues to be analyzed usually stay in their intact states. These fast, instant, low-invasive properties of REIMS help doctors to decide which region should be removed during surgery, reducing the possibility of mistakenly getting rid of the healthy tissue from the patient. The combination of electrosurgical knife with REIMS leads to the innovation of intelligent knife (iKnife) technology, which is used to help surgeons in determining the dissection region in the tumor resection surgery. REIMS has been used to distinguish tissues between non-cancerous and cancerous sections. ${ }^{45,46)}$ PCA is the commonly-used strategy to distinguish types of tissues. REIMS technology is also applied to distinguish and identify the tissues from different organs. By utilizing REIMS, molecular species that can be found from liver, breast and lung tissue are mainly composed by phosphatidylcholines (PC), phosphatidylserines (PS) and phosphatidylethanolamines (PE). As only few ion species are tissuespecific, MS characterization of tissues is usually at profiling level, in which a group of ions (or MS features), rather than a specific ion, is used to determine the tissue types. ${ }^{44,47)}$ The relative intensities of those common ions from the family of glycerophospholipid are significantly varied from different types of tissues. ${ }^{44)}$ It is difficult to compare the performance between DESI and REIMS, as they have different ionization mechanisms and spectral features. ${ }^{43)}$ After all, their applicability to biological samples provide good platforms for clinical applications. ${ }^{44)}$

It is noteworthy that REIMS cannot only be used for mapping of the surface contour but also go into the inner part of samples, which makes it exceptional to the other AIMS methods. REIMS-based endoscopic approach has been developed as a potential instrument for the surgery to investigate MS features of organs in human body. An ex vivo performance test reported in 2015 by Balog et al. ${ }^{45)}$ revealed that this novel endoscopic technique successfully distinguishes different types of gastric tissues using a porcine stomach model. The differences in the expression levels of triglyceride phosphatidylinositol, and phosphatidylethanolamines were used as designated markers of gastric cancers in this study. Furthermore, an in vivo test was also conducted to make the distinction between colonic polyps and healthy mucosal layers.

\section{TOUCH SPRAY IONIZATION (TSI) AND PROBE-ESI (PESI)}

Touch spray ionization (TSI) and probe electrospray ionization (PESI) are two similar ionization methods recently developed. ${ }^{48)}$ Both of these two techniques have advantages of low-invasiveness, sample cost-effective and ability of high-throughput screening. In terms of TSI, a metallic tip is used as a sample-loading substrate. After the tip contacts with the sample, the tip surface absorbs small pieces of the sample on the tip surface. It is then aligned with the inlet of mass spectrometer at a distance of 5-20 mm. To generate ions for MS analysis, the tip is rinsed with a small volume of solvent (usually only about $1 \mu \mathrm{L}$ ), and a high voltage about $3-5 \mathrm{kV}$ is applied to produce the spray current.

The protocol of PESI resembles that of TSI-MS. In PESI, the sampling needle not only contacts the sample surface, but also punctures the sample. Needles used in this technique usually utilize commercialized disposable acupuncture needles, which are originally used for traditional Chinese medical therapy by inserting the needles into human body. To minimize the invasiveness, the diameter of the needles is only about $120 \mu \mathrm{m}$. As the duration of the electrospray current in such probe-based ESI methods are usually short, usually only few milliseconds both TSI and PESI can be assembled. To improve the quality of data, first, 
the needle needs to be fixed to a stainless steel tube which can be attached to the needle holder of the linear actuator with a precision crimper. Second, a linear motor actuator can move the needle up and down alone a vertical axis to repeat the sampling-scanning procedure, extend the volume of sample ionized and accumulate the total time duration of data acquisition, so as to improve the quality of data. ${ }^{49)}$ It is also a common feature of most of the ambient ionization methods, in which the position of probe tip has an influence on ionization efficiency, ion transmission rate, signal intensity and ultimately quality of data.

Surface properties of the sampling probe, such as hydrophobicity or hydrophilicity, determine the extraction efficiency and sample loading quality. ${ }^{50)}$ The probe surface modification by incubating titanium wire with pentafluorophenyl-triethoxysilane makes the surface of probe more hydrophobic, and such modification can be used to adjust the amount and molecular species of sample loading. To avoid clogging, needles are used to replace sampledelivering capillaries, which are largely used in traditional ESI methodology. ${ }^{51)}$ In a common ESI, the surface activity of analytes plays an important role. Ions with higher surface activity, usually more hydrophobic species, tend to migrate toward the surface of droplets, consequently having higher surface concentration than the ion of lower surface activity. As a result, ions of higher surface activity are easier to be desorbed from droplets and become gaseous ions. ${ }^{52,53)}$ Similar to ESI, this ion-selection effect is also found in PESI, in which different molecular species of the analytes attached onto the sample probe are not ionized and introduced into the mass spectrometer at the same time. The analytes with higher surface activity will leave the droplet on the needle earlier. Thus, analytes of lower surface activity remain in the droplet, continuously interact with high voltage from the needle. After charge accumulation, those low surface-active analytes eventually become electrospray and detected by mass spectrometry. ${ }^{50)}$ As a result, time-dependent spectra are obtained, and the correlation between injection time and types of ion species can be verified by the comparison of their extracted ion chromatograms. This property compensates the ion suppression in conventional ESI methodology. In ESI ionization process, the sample solution is continuously supplied and the higher surface-active (hydrophobic) species always dominate, whereas hydrophilic compounds are readily measured in PESI-MS. ${ }^{54)}$

\section{Clinical applications of TSI- and PESI-MS}

Different from DESI or REIMS, that are mostly limited to the detection of lipids in tissue samples, probe-ESI shows an ability to obtain ions of peptides and proteins in biological samples, as analytes of both high and low surface activity are found in PESI. ${ }^{50)}$ Proteins with molecular weight over $5 \mathrm{kDa}$ (insulin, MW: 5730) were detected by PESI. ${ }^{48)}$ This allows PESI to detect species difficult to be analyzed by other ionization methods, making this method more potential in clinical application to the protein level.

The appreciable advantage of TSI-MS is its convenience of in situ sampling, highlighted in several aspects from the literatures. One of which is the discrimination of the prostate tissue between its cancerous and healthy states based on the lipid profiles with a prediction rate achieving over $90 \%{ }^{22,55)}$ Another application is the identification of bacte- rial lipids from strep throat infection and to discriminate the specimen causing inflection. ${ }^{56)}$ The sampling step is just swabbing the patient's throat with metallic swab, which is simple and rapid enough for POCT. ${ }^{56)}$ Furthermore, illicit drugs including morphine, cocaine and methamphetamine can be detected through PESI at ppb level spiked into human plasma. ${ }^{57)}$ PESI is also applied to hepatocellular carcinoma diagnosis. In the cancerous region, the abundance of triacylglycerols (TAGs) related species are significantly increased at $m / z$ 896-927.58) To increase the data acquiring duration, a syringe with extraction solvent can be used to replace the needle in PESI to extract tissue from organs for subsequent ESI. The spray period can last for about $30 \mathrm{~s}$, which is much longer than milliseconds in PESI. Spectra from the healthy and the cancerous kidney tissue using the modified PESI showed characteristic difference in the lipids related regime. ${ }^{59)}$

\section{PAPER SPRAY IONIZATION (PSI)}

In 1963, Guthrie and Susi reported dried blood spots (DBS) as a development of newborn screening for pediatric purposes. ${ }^{60)}$ Since then, sample collection on paper has been explored with various analytical techniques. Particular interest for DBS lies in the pharmaceutical industry to support pharmacokinetics and toxicokinetics studies. ${ }^{61-63)}$ For decades, LC-MS-based methods have been established and used as the standard procedure for quantification of drugs and metabolites in plasma or urine. ${ }^{64)}$ However, the most important issue is the sensitivity related to the sample concentration and volume available from DBS. The significant improvement in sensitivity of current MS instruments is adequate for routine analysis of small molecules in DBS, with some applications also reported from hospitals for therapeutic drug monitoring. ${ }^{65)}$ In the past few years, many instrumental and methodological solutions have been developed in dedicated to DBS. A groundbreaking development was led by Cooks and his coworkers in 2010, who successfully analyzed whole blood at ambient condition to measure drug molecules such as imatinib in whole blood by PSI-MS. ${ }^{66)}$

PSI was characteristics of both ESI and the ambient ionization methods of direct analysis of complex mixtures with almost zero sample preparation. ${ }^{66)}$ A schematic of PSI-MS is shown in Fig. 4. The basic paper spray setup includes a piece of porous paper and a high-voltage power supply. Paper is held by a copper clip and positioned in front of a MS inlet. The sample is placed on the paper, and the copper clip is connected to a high-voltage power supply. Subsequently, electrospray ions are directly produced from the paper surface after elute solvent is added. Analytes of ionic species can be resolved by a mass spectrometer, following data collection and reporting results. From loading sample to reporting results, the whole PSI-MS measurement merely takes a few minutes. ${ }^{66)}$ PSI-MS has been applied to qualitative and quantitative analysis of therapeutic drugs in whole blood and a long-term monitoring of pharmaceuticals. ${ }^{66,67)}$ The simplicity and rapid analysis of PSI-MS make it well suited in POCT applications.

Liu et al. tested various papers as the substrate/sprayer, including filter papers with different pore size, such as grade $1(11 \mu \mathrm{m})$, grade $2(8 \mu \mathrm{m})$, grade $595(4-7 \mu \mathrm{m})$, grade $6(3 \mu \mathrm{m})$, glass microfiber filter paper, and chromatography 


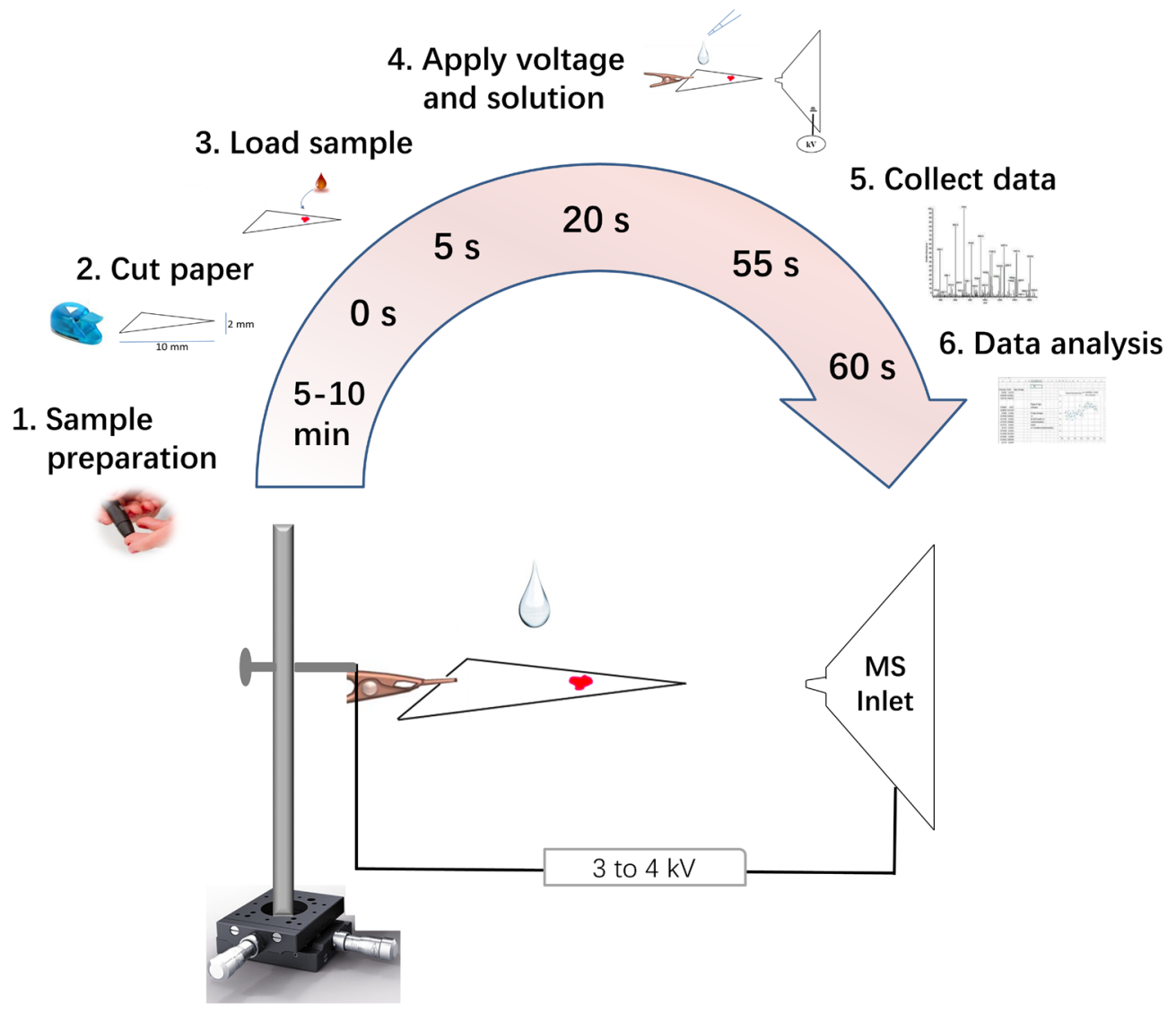

Fig. 4. Schematic overview of PSI-MS analysis.

paper. ${ }^{68)}$ In this case, papers were cut into the same dimension and a $10 \mu \mathrm{L}$ methanol/water $(1: 1, \mathrm{v} / \mathrm{v})$ solution containing cocaine $(200 \mathrm{ng} / \mathrm{mL})$ was added. The results showed that the highest quality spectrum with the highest $S / N$ ratio for cocaine $(\mathrm{m} / \mathrm{z} 304)$ was obtained with chromatography paper, which was selected for the subsequent experiments. The effects of paper geometry, structure and materials have also been extensively investigated to improve the PSI-MS performance. ${ }^{66,68-75)}$

It is relatively difficult for direct AIMS methods to obtain accurate quantitative analysis. This is usually carried out by spiking a known quantity of isotopically labeled standard. However, it is still questionable about the use of internal standard in PSI-MS. Manicke et al. ${ }^{76)}$ have investigated three different methods of adding the internal standard: pretreating the paper, spiking the internal standard into the spray solvent, or adding an internal standard directly in dried blood spot after the blood was thoroughly dried. The result implies that the treatment of the paper with the internal standard prior to spotting the blood has a poorer precision than when it was mixed in the liquid blood.

The amount of sample load and paper size are also important factors for obtaining a stable MS signal and accurate quantitative results. Yang et al. have proved that sample load was dependent on the paper size. ${ }^{77)}$ In their study, they have used $200 \mathrm{ng} / \mathrm{mL}$ cocaine in a $10 \mu \mathrm{L}$ methanol/water $(1: 1$, $\mathrm{v} / \mathrm{v})$ solution to explore the relationship between sample load and paper substrate size for quantitative analysis. Three homologous triangular paper substrates of different areas were prepared: $7.5 \times 8.0 \mathrm{~mm}, 11.9 \times 12.7 \mathrm{~mm}$ and $16.8 \times 17.9 \mathrm{~mm}$ (height $\times$ base). For each size of paper substrate, three dif- ferent blood sample amounts $(0.50,1.25,2.50 \mu \mathrm{L})$ were preloaded on the substrate which were then dried and tested. The results showed that $7.5 \times 8.0 \mathrm{~mm}$ triangular paper had reached its saturation sample load for volumes between 1.25 and $2.5 \mu \mathrm{L}$ with a $10 \mu \mathrm{L}$ volume of solvent.

A typical PSI process contains sample collection, analytes separation, and analytes ionization. An investigation of the impacts to PSI-MS performance by the substrates, solvents and elution methods were reported by Ren et al. ${ }^{72)} \mathrm{A}$ higher voltage $( \pm 3.5 \mathrm{kV})$ is usually applied to PSI-MS. Espy et al. have particularly focused on the voltage applied for spraying and the correct positioning of the paper tip in front of the inlet of the MS spectrometer. ${ }^{78)}$ In addition, the angle of the paper tip also plays a key role in the generation of the spray. In their results showed that paper spray operates in two distinct spray modes. Mode 1 occurs in solvent-rich system, a number of spray jets emerge near the sharp end of the paper triangle and the droplet size varies from 0.5 to $1.9 \mu \mathrm{m}$, whereas mode 2 occurs in solvent-deficient system, and only one Taylor cone is formed while the ion current increases and reaches to the value of $0.8 \mu \mathrm{A}$. The cone-jet diameters were approximately $1-10 \mu \mathrm{m}$ in diameter, and smaller but out-of-focus jets are also produced. ${ }^{78,79)}$ The electrospray droplet size is dependent on not only applied voltage, but also the solvent composition and the flow rate. The use of $100 \%$ water in conjunction in PSI is difficult unless salt is added to the water to increase conductivity. The effect of spray solvent types to analyte species detected by PSI-MS were tested by Li et al. ${ }^{80)}$ The results indicate that it is important to choose the suitable solvent for the target compounds. In many cases, water/methanol mixture is used 
as the solvent in PSI-MS. ${ }^{81)}$

\section{Clinical applications of PSI-MS}

Ever since PSI-MS was first reported, it has been used to monitor a wide variety of molecules in blood. For example, Cooks group has successfully demonstrated that PSI-MS is able to obtain doped imatinib in whole blood sample. ${ }^{66)}$ In this case, the authors used $0.4 \mathrm{~mL}$ of whole blood containing $4 \mu \mathrm{g} / \mathrm{mL}$ of imatinib to be identified and quantified by the MS/MS fragments. Quantitative analysis was performed by isotope-labeled imatinib standard within only few $\mu \mathrm{L}$ of the whole blood sample. Total analyte amounts are from only $50 \mathrm{pg}$ to $5 \mathrm{ng}$, and the MS signals can last for several minutes. High-quality mass spectra and as well as MS/MS analysis were obtained from a variety of paper surfaces.

PSI-MS is thought to be alternative to LC-MS in clinical and drug discovery laboratories for dried blood spot samples. Methods used for the determination of drugs should be sensitive, accurate, and precise. In this regard, an approach was evaluated for quantifying a variety of drugs in DBS with paper spray by Manicke et al. ${ }^{82)}$ In this study, the detection limits ranged from $<100 \mathrm{pg} / \mathrm{mL}$ for proguanil and benzothenium to $>100 \mathrm{ng} / \mathrm{mL}$ for acetaminophen and ibuprofen. The lower limits of detection (LOD) were around 0.25 to $0.75 \mathrm{ng} / \mathrm{mL}$ in this case.

Acylcarnitines exist in many kinds of biological fluids. Plasma or serum are the preferred sample matrix for acylcarnitines profiling in the diagnosis of fatty acid oxidation disorders in newborn screening. ${ }^{83)}$ Currently, the flow injection ESI-MS-based technique is the main approach implemented for acylcarnitines analysis. ${ }^{84,85)}$ Alternatively, Yang et al. proposed to quantify ten different acylcarnitines in serum and whole blood from C2 to C18 side-chain acylcarnitines with PSI-MS. ${ }^{67)}$ The results indicated that solvent compositions and sample load are critical factors for acylcarnitine analysis in serum and in blood. The quantification of the acylcarnitines was achieved using deuterated internal standards with only $0.5 \mu \mathrm{L}$ of serum or blood sample. It is worth noting that the limits of detection obtained from both serum and blood are much lower than the clinically validated cutoff value, and acceptable linearity $\left(R^{2}>0.95\right)$ and good reproducibility (RSD, $10 \%$ ) were achieved in the concentration ranges tested. These results show that PSI-MS has the potential to be a new technique for rapid assessment of acylcarnitines in newborn screening.

\section{TWO-STEP ESI DROPLET-ASSISTED DESORP- TION IONIZATION AND ITS CLINICAL AP- PLICATIONS}

For the methods mentioned earlier in the article, the desorption and the ionization of the analytes mostly occur in a single step. However, there are some AIMS technologies utilizing a two-step desorption/ionization approach, in which analytes are mobilized in forms of neutral aerosols or microdroplets before a high voltage is applied. For example, the plume containing neutral analyte molecules can be first generated by laser ablation or thermal desorption at atmospheric pressure and then followed by the ionization step, which is usually conducted by a stream of electrospray droplets. Here we introduce some of these methods, including extractive electrospray ionization (EESI), ${ }^{86-88)}$ electrospray- assisted laser desorption/ionization (ELDI), ${ }^{89)}$ laser ablation electrospray ionization (LAESI), ${ }^{90,91)}$ and thermal desorption electrospray ionization (TD-ESI). ${ }^{93,94)}$

The main component of EESI contains two channels: one is an ESI channel with high voltage to supply electrospray ion donors; the other one is a sample transferring channel offering nebulized analyte microdroplets. The two channels are mixed together to ionize the analyte before they are introduced into the mass spectrometer. ${ }^{86)}$ EESI-MS has been applied to analyze biological samples including urine ${ }^{86)}$ and compounds on human skin. ${ }^{87)}$ EESI also shows the clinical application. For instance, the in vivo human breath analysis by EESI reveals that the concentration of acetonitrile in the breath of smokers and non-smokers can be distinguished. ${ }^{88)}$

ELDI $^{89)}$ and $\mathrm{LAESI}^{90)}$ are first reported in 2005 and 2007 respectively. Both of the techniques utilize a laser beam to generate a plume of analytes under ambient environment. In the configuration of these techniques, samples are first ablated by an UV laser (in ELDI) or a mid-IR laser (in LAESI). Subsequently, the analytes in the plume of aerosols are ionized and brought into the mass spectrometer by a stream of electrospray droplets. It has been demonstrated that LAESI-MS can obtain the signals of multiple-charged proteins, including human hemoglobin subunits $(\sim 15 \mathrm{kDa})$ and human serum albumin $(\sim 67 \mathrm{kDa})$, in untreated whole blood samples. ${ }^{90)}$ LAESI-MS has also shown its ability to obtain the intact ion signals of bacteria-derived biomolecules, including metabolites, lipids and peptides. ${ }^{91)}$

TD-ESI utilizes a metallic probe to sweep the sample surface to remove and transferred the molecules of interests for subsequent MS monitoring. ${ }^{92)}$ Analytes attached on the probe are thermally desorbed, and then ionized by the electrospray droplets. TD-ESI-MS is an ultra-sensitive, which the limit of detection for methamidophos was reported as $1 \mathrm{ppb},{ }^{92)}$ and convenient ionization method that can be easily applied to either solid ${ }^{93)}$ or liquid ${ }^{94)}$ samples. It has been shown that TD-ESI-MS can promptly identify the component of pesticides in human oral fluid ${ }^{92)}$ and medications in gastric lavage content, ${ }^{94)}$ providing an alternative approach for physicians in emergency room to make decision without delay.

These technologies show a capability of much greater applications in terms of sensitivity and selectivity. Since only analytes which are able to be desorbed from the bulk sample surface will be ionized by the following electrospray droplets, compounds that are not easily ionized by ESI may be monitored. Furthermore, this mechanical feature makes them possible to reduce the matrix effect which is usually faced in conventional ESI methods. As a result, their tolerance to the interference from the complex matrix in biological samples allows them to be a possible approach in the clinical analysis using AIMS.

\section{FUTURE PERSPECTIVE}

AIMS is characteristic for its speed and ease of use together that allows a rapid, direct, and quantitative analysis of complex biological samples. A relatively diverse application is currently available for many AIMS approaches as highlighted by Klampfl et al. ${ }^{81)}$ It has been demonstrated that AIMS could pave the way for fast and quantitative analysis in clinical laboratories and POCT, in particular, 
with highly simplified procedure. However, it cannot be denied that this new technical tool still has many challenges and limitations in terms of sensitivity, cost of MS instrumentation, and range of mass. There are a number of studies responding to these challenges and could provide some possible solutions. Cooper group and Eberlin group have both proposed that by interfacing a chip-based high-field asymmetric waveform ion mobility spectrometry (FAIMS) device with AIMS, the sensitivity of the detection especially to large molecules are significantly improved. ${ }^{95,96)}$ Furthermore, miniaturized mass spectrometry not only compresses the benchtop system but makes the instrument cost become possible for daily test. ${ }^{97,98)}$ We are confident that with the improvements in these aspects, AIMS may be widely accepted as a method for routine clinical use in emergency units, or even outpatient departments where the rapid turnaround times of the tests are more essential than in the hospital settings.

Currently, there are two seemingly opposite extreme trends in clinical diagnostics: (1) centralized laboratory testing-total laboratory automation (TLA) and consolidation of testing in centralized laboratories, ${ }^{99)}$ and (2) POCTdecentralizing the testing to various near-patient sites. ${ }^{100)}$ More and more reports showed that POCT is preferred when testing results are needed in urgent and not feasible using conventional testing procedures. ${ }^{100)}$ As shown in Fig. 5 , the clinical decision-making in centralized laboratories is often time-consuming and subject to be postponed because of many of the pre- and post-analytical testing. Meanwhile, the ideal of POCT is to support a low-spending/highperformance hospital system, and can be especially useful in the emergency department. This ideal is becoming true with the utilization of AIMS. Many of the steps in centralized laboratories can possibly be re-directed into only few steps using AIMS. We refer this new strategy as AIMS-directed distributed test (Fig. 5). Contrary to the centralized laboratory test, samples from patients or individuals are not accumulated or waiting to be transported before clinical test. Instead, fresh samples with almost zero or only minimal preparation are analyzed at community clinics by nursing staff as soon as they are collected. Expensive mass spectrometers of high resolving power and ultrafast scanning rate are not required, whereas low cost mass analyzers or even portable mass spectrometers equipped with AIMS can be easily implemented in a doctor's office for such on-site tests.

In the end, we foresee two main clinical applications of AIMS in the next decade: drug testing and POCT development. The first one is aiming for a direct identification of pharmaceutical substances either legally or illegally used, at extremely short timescale. In the second one, with the implementation of AIMS on miniature mass analyzers in clinical diagnostic, POCT outside the centralized laboratory or even the hospitals is possible. ${ }^{69,97)}$ As the field continues to mature, we urge the researchers and medical institutions to strive to make public their own AIMS results to unify and standardize the data format. As such, a low-cost and high efficient "mass-omic" screening targeting for personal medicine could be made and become routine.

\section{Centralized Laboratory Test}

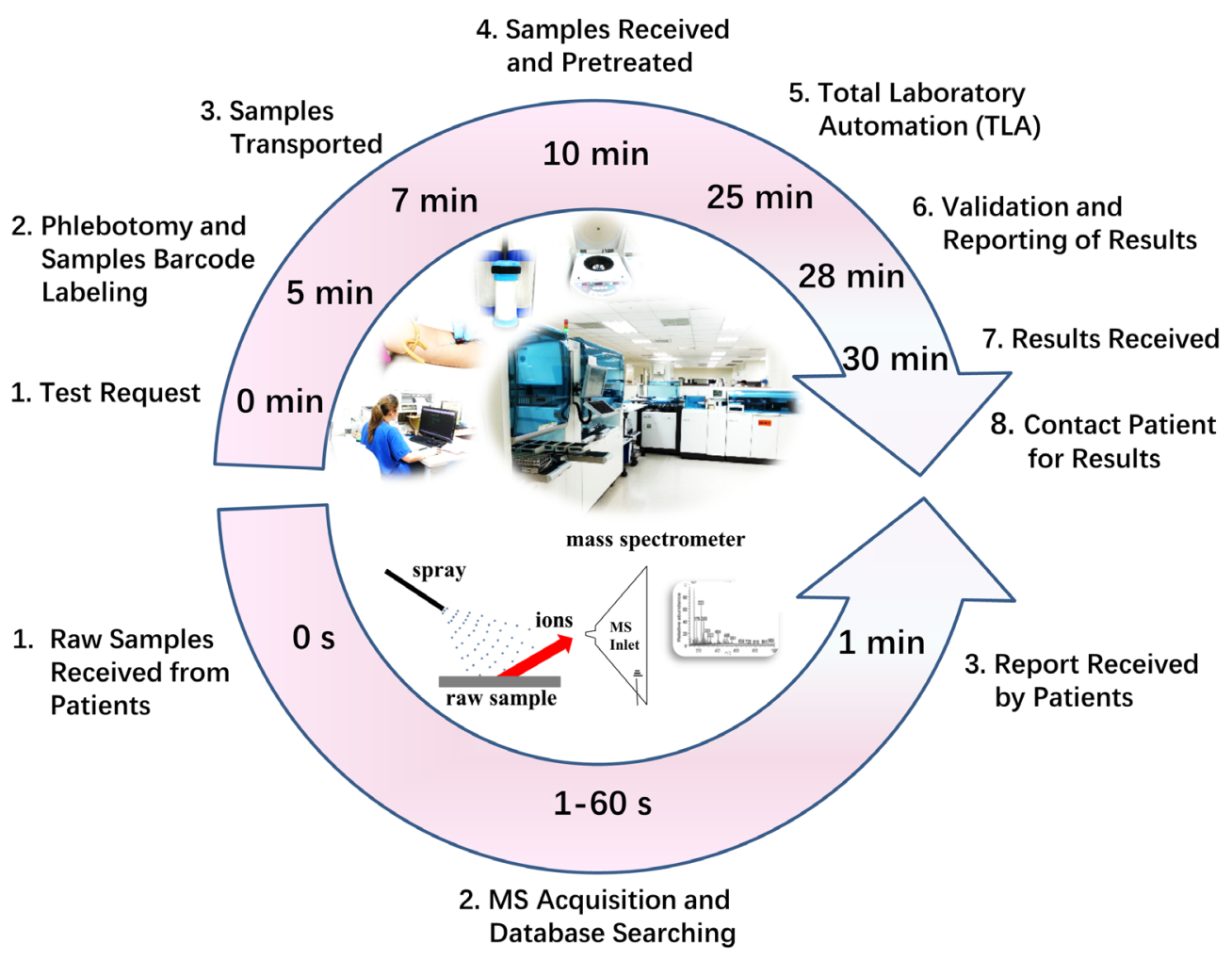

AIMS-directed Distributed Test

Fig. 5. Flowchart of centralized laboratory test (top) and AIMS-directed distributed test (bottom). 


\section{REFERENCES}

1) M. Wagner, D. Tonoli, E. Varesio, G. Hopfgartner. The use of mass spectrometry to analyze dried blood spots. Mass Spectrom. Rev. 35: 361-438, 2016.

2) C. C. Hsu, P. C. Dorrestein. Visualizing life with ambient mass spectrometry. Curr. Opin. Biotechnol. 31: 24-34, 2015.

3) A. T. Lebedev. Ambient ionization mass spectrometry. Russ. Chem. Rev. 84: 665-692, 2015.

4) M. Z. Huang, S. C. Cheng, Y. T. Cho, J. Shiea. Ambient ionization mass spectrometry: A tutorial. Anal. Chim. Acta 702: 1-15, 2011.

5) Z. Takáts, J. M. Wiseman, B. Gologan, R. G. Cooks. Mass spectrometry sampling under ambient conditions with desorption electrospray ionization. Science 306: 471-473, 2004.

6) R. B. Cody, J. A. Laramee, H. D. Durst. Versatile new ion source for the analysis of materials in open air under ambient conditions. Anal. Chem. 77: 2297-2302, 2005.

7) D. R. Ifa, L. S. Eberlin. Ambient ionization mass spectrometry for cancer diagnosis and surgical margin evaluation. Clin. Chem. 62: 111-123, 2016

8) M. Shariatgorji, N. Strittmatter, A. Nilsson, P. Kallback, A. Alvarsson, X. Zhang, T. Vallianatou, P. Svenningsson, R. J. Goodwin, P. E. Andren. Simultaneous imaging of multiple neurotransmitters and neuroactive substances in the brain by desorption electrospray ionization mass spectrometry. Neuroimage 136: 129-138, 2016

9) M. Manikandan, Z. Kazibwe, N. Hasan, A. Deenadayalan, J. Gopal, T. Pradeep, S. Chun. Biological Desorption Electrospray Ionization Mass Spectrometry (DESI MS)-Unequivocal role of crucial ionization factors, solvent system and substrates. Trends Analyt. Chem. 78: 109-119, 2016.

10) C. Wu, D. R. Ifa, N. E. Manicke, R. G. Cooks. Rapid, direct analysis of cholesterol by charge labeling in reactive desorption electrospray ionization. Anal. Chem. 81: 7618-7624, 2009.

11) K. Heaton, C. Solazzo, M. J. Collins, J. Thomas-Oates, E. T. Bergström. Towards the application of desorption electrospray ionisation mass spectrometry (DESI-MS) to the analysis of ancient proteins from artefacts. J. Archaeol. Sci. 36: 2145-2154, 2009

12) D. J. Weston. Ambient ionization mass spectrometry: Current understanding of mechanistic theory; Analytical performance and application areas. Analyst (Lond.) 135: 661-668, 2010.

13) K. Chughtai, R. M. Heeren. Mass spectrometric imaging for biomedical tissue analysis. Chem. Rev. 110: 3237-3277, 2010.

14) L. S. Eberlin, R. J. Tibshirani, J. Zhang, T. A. Longacre, G. J. Berry, D. B. Bingham, J. A. Norton, R. N. Zare, G. A. Poultsides. Molecular assessment of surgical-resection margins of gastric cancer by mass-spectrometric imaging. Proc. Natl. Acad. Sci. U.S.A. 111: 2436-2441, 2014.

15) J. Liu, J. Gingras, K. P. Ganley, R. Vismeh, Y. Teffera, Z. Zhao. Whole-body tissue distribution study of drugs in neonate mice using desorption electrospray ionization mass spectrometry imaging. Rapid Commun. Mass Spectrom. 28: 185-190, 2014.

16) L. S. Eberlin, D. R. Ifa, C. Wu, R. G. Cooks. Three-dimensional vizualization of mouse brain by lipid analysis using ambient ionization mass spectrometry. Angew. Chem. Int. Ed. Engl. 49: $873-876,2010$

17) D. I. Campbell, C. R. Ferreira, L. S. Eberlin, R. G. Cooks. Improved spatial resolution in the imaging of biological tissue using desorption electrospray ionization. Anal. Bioanal. Chem. 404: 389-398, 2012.

18) J. M. Wiseman, C. A. Evans, C. L. Bowen, J. H. Kennedy. Direct analysis of dried blood spots utilizing desorption electrospray ionization (DESI) mass spectrometry. Analyst (Lond.) 135: 720-725, 2010.

19) H. Chen, I. Cotte-Rodriguez, R. G. Cooks. cis-Diol functional group recognition by reactive desorption electrospray ionization (DESI). Chem. Commun. (Camb.) 6: 597-599, 2006.

20) D. Lostun, C. J. Perez, P. Licence, D. A. Barrett, D. R. Ifa. Reactive DESI-MS imaging of biological tissues with dicationic ionpairing compounds. Anal. Chem. 87: 3286-3293, 2015.

21) D. Calligaris, D. Caragacianu, X. Liu, I. Norton, C. J. Thompson, A. L. Richardson, M. Golshan, M. L. Easterling, S. Santagata, D. A. Dillon, F. A. Jolesz, N. Y. Agar. Application of desorption electrospray ionization mass spectrometry imaging in breast cancer margin analysis. Proc. Natl. Acad. Sci. U.S.A. 111: 1518415189, 2014.

22) K. S. Kerian, A. K. Jarmusch, V. Pirro, M. O. Koch, T. A. Masterson, L. Cheng, R. G. Cooks. Differentiation of prostate cancer from normal tissue in radical prostatectomy specimens by desorption electrospray ionization and touch spray ionization mass spectrometry. Analyst (Lond.) 140: 1090-1098, 2015

23) S. Santagata, L. S. Eberlin, I. Norton, D. Calligaris, D. R. Feldman, J. L. Ide, X. Liu, J. S. Wiley, M. L. Vestal, S. H. Ramkissoon, D. A. Orringer, K. K. Gill, I. F. Dunn, D. Dias-Santagata, K. L. Ligon, F. A. Jolesz, A. J. Golby, R. G. Cooks, N. Y. Agar. Intraoperative mass spectrometry mapping of an onco-metabolite to guide brain tumor surgery. Proc. Natl. Acad. Sci. U.S.A. 111 11121-11126, 2014.

24) L. S. Eberlin, I. Norton, A. L. Dill, A. J. Golby, K. L. Ligon, S. Santagata, R. G. Cooks, N. Y. Agar. Classifying human brain tumors by lipid imaging with mass spectrometry. Cancer Res. 72 645-654, 2012.

25) P. J. Roach, J. Laskin, A. Laskin. Nanospray desorption electrospray ionization: An ambient method for liquid-extraction surface sampling in mass spectrometry. Analyst (Lond.) 135: 2233-2236, 2010.

26) J. Laskin, B. S. Heath, P. J. Roach, L. Cazares, O. J. Semmes. Tissue imaging using nanospray desorption electrospray ionization mass spectrometry. Anal. Chem. 84: 141-148, 2012.

27) G. J. Van Berkel, V. Kertesz, K. A. Koeplinger, M. Vavrek, A. N. Kong. Liquid microjunction surface sampling probe electrospray mass spectrometry for detection of drugs and metabolites in thin tissue sections. J. Mass Spectrom. 43: 500-508, 2008.

28) W. Rao, N. Pan, Z. Yang. High resolution tissue imaging using the single-probe mass spectrometry under ambient conditions. J. Am. Soc. Mass Spectrom. 26: 986-993, 2015.

29) G. J. Van Berkel, V. Kertesz. Continuous-flow liquid microjunction surface sampling probe connected online with high-performance liquid chromatography/mass spectrometry for spatially resolved analysis of small molecules and proteins. Rapid Commun. Mass Spectrom. 27: 1329-1334, 2013.

30) C. C. Hsu, N. M. White, M. Hayashi, E. C. Lin, T. Poon, I. Banerjee, J. Chen, S. L. Pfaff, E. R. Macagno, P. C. Dorrestein. Microscopy ambient ionization top-down mass spectrometry reveals developmental patterning. Proc. Natl. Acad. Sci. U.S.A. 110: 14855-14860, 2013.

31) C. C. Hsu, P. T. Chou, R. N. Zare. Imaging of proteins in tissue samples using nanospray desorption electrospray ionization mass spectrometry. Anal. Chem. 87: 11171-11175, 2015.

32) E. P. Dutkiewicz, K. T. Hsieh, Y. S. Wang, H. Y. Chiu, P. L. Urban. Hydrogel micropatch and mass spectrometry-assisted screening for psoriasis-related skin metabolites. Clin. Chem. 62: 1120-1128, 2016.

33) J. H. Gross. Direct analysis in real time-A critical review on DART-MS. Anal. Bioanal. Chem. 406: 63-80, 2014.

34) F. J. Andrade, J. T. Shelley, W. C. Wetzel, M. R. Webb, G. Gamez, S. J. Ray, G. M. Hieftje. Atmospheric pressure chemical ionization source. 1. Ionization of compounds in the gas phase. Anal. Chem. 80: 2646-2653, 2008.

35) C. M. Jones, F. M. Fernandez. Transmission mode direct analysis in real time mass spectrometry for fast untargeted metabolic fingerprinting. Rapid Commun. Mass Spectrom. 27: 1311-1318, 2013. 
36) Y. Q. Song, J. Liao, C. Zha, B. Wang, C. C. Liu. A novel approach to determine the tyrosine concentration in human plasma by DART-MS/MS. Anal. Methods 7: 1600-1605, 2015.

37) L. Zhang, W. Yong, J. Liu, S. Wang, Q. Chen, T. Guo, J. Zhang, T. Tan, H. Su, Y. Dong. Determination of dicyandiamide in powdered milk using direct analysis in real time quadrupole timeof-flight tandem mass spectrometry. J. Am. Soc. Mass Spectrom. 26: 1414-1422, 2015.

38) Y. Wang, C. Li, L. Huang, L. Liu, Y. Guo, L. Ma, S. Liu. Rapid identification of traditional Chinese herbal medicine by direct analysis in real time (DART) mass spectrometry. Anal. Chim. Acta 845: 70-76, 2014.

39) M. Zhou, J. F. McDonald, F. M. Fernandez. Optimization of a direct analysis in real time/time-of-flight mass spectrometry method for rapid serum metabolomic fingerprinting. J. Am. Soc. Mass Spectrom. 21: 68-75, 2010.

40) K. C. Schäfer, J. Dénes, K. Albrecht, T. Szaniszló, J. Balog, R. Skoumal, M. Katona, M. Tóth, L. Balogh, Z. Takáts. In vivo, in situ tissue analysis using rapid evaporative ionization mass spectrometry. Angew. Chem. Int. Ed. Engl. 48: 8240-8242, 2009.

41) J. Balog, L. Sasi-Szabó, J. Kinross, M. R. Lewis, L. J. Muirhead, K. Veselkov, R. Mirnezami, B. Dezso, L. Damjanovich, A. Darzi, J. K. Nicholson, Z. Takáts. Intraoperative tissue identification using rapid evaporative ionization mass spectrometry. Sci. Transl. Med. 5: 194ra93, 2013

42) N. Strittmatter, A. Lovrics, J. Sessler, J. S. McKenzie, Z. Bodai, M. L. Doria, N. Kucsma, G. Szakacs, Z. Takats. Shotgun lipidomic profiling of the NCI60 cell line panel using rapid evaporative ionization mass spectrometry. Anal. Chem. 88: 7507-7514, 2016.

43) O. Golf, N. Strittmatter, T. Karancsi, S. D. Pringle, A. V. Speller, A. Mroz, J. M. Kinross, N. Abbassi-Ghadi, E. A. Jones, Z. Takats. Rapid evaporative ionization mass spectrometry imaging platform for direct mapping from bulk tissue and bacterial growth media. Anal. Chem. 87: 2527-2534, 2015.

44) J. Balog, T. Szaniszlo, K. C. Schaefer, J. Denes, A. Lopata, L. Godorhazy, D. Szalay, L. Balogh, L. Sasi-Szabo, M. Toth, Z. Takats. Identification of biological tissues by rapid evaporative ionization mass spectrometry. Anal. Chem. 82: 7343-7350, 2010.

45) J. Balog, S. Kumar, J. Alexander, O. Golf, J. Huang, T. Wiggins, N. Abbassi-Ghadi, A. Enyedi, S. Kacska, J. Kinross, G. B. Hanna, J. K. Nicholson, Z. Takats. In vivo endoscopic tissue identification by rapid evaporative ionization mass spectrometry (REIMS). Angew. Chem. Int. Ed. Engl. 54: 11059-11062, 2015.

46) Z. Takats, J. Denes, J. Kinross. Identifying the margin: A new method to distinguish between cancerous and noncancerous tissue during surgery. Future Oncol. 8: 113-116, 2012.

47) A. M. Hicks, C. J. DeLong, M. J. Thomas, M. Samuel, Z. Cui. Unique molecular signatures of glycerophospholipid species in different rat tissues analyzed by tandem mass spectrometry. Biochim. Biophys. Acta 1761: 1022-1029, 2006.

48) K. Hiraoka, K. Nishidate, K. Mori, D. Asakawa, S. Suzuki. Development of probe electrospray using a solid needle. Rapid Commun. Mass Spectrom. 21: 3139-3144, 2007.

49) M. K. Mandal, S. Saha, K. Yoshimura, Y. Shida, S. Takeda, H. Nonami, K. Hiraoka. Biomolecular analysis and cancer diagnostics by negative mode probe electrospray ionization. Analyst (Lond.) 138: 1682-1688, 2013.

50) M. K. Mandal, L. C. Chen, K. Hiraoka. Sequential and exhaustive ionization of analytes with different surface activity by probe electrospray ionization. J. Am. Soc. Mass Spectrom. 22: 1493-1500, 2011.

51) J. Jeng, C. H. Lin, J. Shiea. Electrospray from nanostructured tungsten oxide surfaces with ultralow sample volume. Anal. Chem. 77: 8170-8173, 2005

52) P. Kebarle. A brief overview of the present status of the mechanisms involved in electrospray mass spectrometry. J. Mass Spectrom. 35: 804-817, 2000.
53) S. Zhou, K. D. Cook. A mechanistic study of electrospray mass spectrometry: Charge gradients within electrospray droplets and their influence on ion response. J. Am. Soc. Mass Spectrom. 12: 206-214, 2001

54) N. B. Cech, C. G. Enke. Effect of affinity for droplet surfaces on the fraction of analyte molecules charged during electrospray droplet fission. Anal. Chem. 73: 4632-4639, 2001.

55) K. S. Kerian, A. K. Jarmusch, R. G. Cooks. Touch spray mass spectrometry for in situ analysis of complex samples. Analyst (Lond.) 139: 2714-2720, 2014.

56) A. K. Jarmusch, V. Pirro, K. S. Kerian, R. G. Cooks. Detection of strep throat causing bacterium directly from medical swabs by touch spray-mass spectrometry. Analyst (Lond.) 139: 4785-4789, 2014.

57) S. Saha, M. K. Mandal, K. Hiraoka. Direct detection of trace level illicit drugs in human body fluids by probe electrospray ionization mass spectrometry (PESI-MS). Anal. Methods 5: 4731-4738, 2013.

58) K. Yoshimura, M. K. Mandal, M. Hara, H. Fujii, L. C. Chen, K. Tanabe, K. Hiraoka, S. Takeda. Real-time diagnosis of chemically induced hepatocellular carcinoma using a novel mass spectrometry-based technique. Anal. Biochem. 441: 32-37, 2013.

59) J. Liu, R. G. Cooks, Z. Ouyang. Biological tissue diagnostics using needle biopsy and spray ionization mass spectrometry. Anal. Chem. 83: 9221-9225, 2011.

60) R. Guthrie, A. Susi. A simple phenylalanine method for detecting phenylketonuria in large populations of newborn infants. Pediatrics 32: 338-343, 1963.

61) M. Barfield, N. Spooner, R. Lad, S. Parry, S. Fowles. Application of dried blood spots combined with HPLC-MS/MS for the quantification of acetaminophen in toxicokinetic studies. J. Chromatogr. B Analyt. Technol. Biomed. Life Sci. 870: 32-37, 2008.

62) A. A. Alfazil, R. A. Anderson. Stability of benzodiazepines and cocaine in blood spots stored on filter paper. J. Anal. Toxicol. 32: 511-515, 2008

63) W. Li, F. L. Tse. Dried blood spot sampling in combination with LC-MS/MS for quantitative analysis of small molecules. Biomed. Chromatogr. 24: 49-65, 2010.

64) G. Hopfgartner, E. Bourgogne. Quantitative high-throughput analysis of drugs in biological matrices by mass spectrometry. Mass Spectrom. Rev. 22: 195-214, 2003.

65) P. M. Edelbroek, J. van der Heijden, L. M. Stolk. Dried blood spot methods in therapeutic drug monitoring: Methods, assays, and pitfalls. Ther. Drug Monit. 31: 327-336, 2009.

66) H. Wang, J. Liu, R. G. Cooks, Z. Ouyang. Paper spray for direct analysis of complex mixtures using mass spectrometry. Angew. Chem. Int. Ed. Engl. 49: 877-880, 2010.

67) Q. Yang, N. E. Manicke, H. Wang, C. Petucci, R. G. Cooks, Z. Ouyang. Direct and quantitative analysis of underivatized acylcarnitines in serum and whole blood using paper spray mass spectrometry. Anal. Bioanal. Chem. 404: 1389-1397, 2012.

68) J. Liu, H. Wang, N. E. Manicke, J. M. Lin, R. G. Cooks, Z. Ouyang. Development, characterization, and application of paper spray ionization. Anal. Chem. 82: 2463-2471, 2010.

69) Y. Ren, S. Chiang, W. Zhang, X. Wang, Z. Lin, Z. Ouyang. Paper-capillary spray for direct mass spectrometry analysis of biofluid samples. Anal. Bioanal. Chem. 408: 1385-1390, 2016.

70) Q. Wang, Y. Zheng, X. Zhang, X. Han, T. Wang, Z. Zhang. A silica coated paper substrate: Development and its application in paper spray mass spectrometry for rapid analysis of pesticides in milk. Analyst (Lond.) 140: 8048-8056, 2015.

71) P. H. Lai, P. C. Chen, Y. W. Liao, J. T. Liu, C. C. Chen, C. H. Lin. Comparison of gampi paper and nanofibers to chromatography paper used in paper spray-mass spectrometry. Int. J. Mass Spectrom. 375: 14-17, 2015

72) Y. Ren, H. Wang, J. Liu, Z. Zhang, M. N. McLuckey, Z. Ouyang. Analysis of biological samples using paper spray mass spectrometry: An investigation of impacts by the substrates, solvents and 
elution methods. Chromatographia 76: 1339-1346, 2013.

73) Y. Zheng, X. Zhang, H. Yang, X. Liu, X. Zhang, Q. Wang, Z. Zhang. Facile preparation of paper substrates coated with different materials and their applications in paper spray mass spectrometry. Anal. Methods 7: 5381-5386, 2015.

74) J. Ji, L. Nie, L. Liao, R. Du, B. Liu, P. Yang. Ambient ionization based on mesoporous graphene coated paper for therapeutic drug monitoring. J. Chromatogr. B Analyt. Technol. Biomed. Life Sci. 1015-1016: 142-149, 2016.

75) Y. Zheng, Q. Wang, X. Wang, Y. Chen, X. Wang, X. Zhang, Z. Bai, X. Han, Z. Zhang. Development and application of zirconia coated paper substrate for high sensitivity analysis of therapeutic drugs in dried blood spots. Anal. Chem. 88: 7005-7013, 2016.

76) N. E. Manicke, Q. A. Yang, H. Wang, S. Oradu, Z. Ouyang, R. G. Cooks. Assessment of paper spray ionization for quantitation of pharmaceuticals in blood spots. Int. J. Mass Spectrom. 300: 123-129, 2011.

77) Q. Yang, H. Wang, J. D. Maas, W. J. Chappell, N. E. Manicke, R. G. Cooks, Z. Ouyang. Paper spray ionization devices for direct, biomedical analysis using mass spectrometry. Int. J. Mass Spectrom. 312: 201-207, 2012.

78) R. D. Espy, A. R. Muliadi, Z. Ouyang, R. G. Cooks. Spray mechanism in paper spray ionization. Int. J. Mass Spectrom. 325: $167-171,2012$.

79) K. Tang, A. Gomez. Monodisperse electrosprays of low electric conductivity liquids in the cone-jet mode. J. Colloid Interface Sci. 184: 500-511, 1996.

80) A. Li, H. Wang, Z. Ouyang, R. G. Cooks. Paper spray ionization of polar analytes using non-polar solvents. Chem. Commun. (Camb.) 47: 2811-2813, 2011.

81) C. W. Klampfl, M. Himmelsbach. Direct ionization methods in mass spectrometry: An overview. Anal. Chim. Acta 890: 44-59, 2015

82) N. E. Manicke, P. Abu-Rabie, N. Spooner, Z. Ouyang, R. G. Cooks. Quantitative analysis of therapeutic drugs in dried blood spot samples by paper spray mass spectrometry: An avenue to therapeutic drug monitoring. J. Am. Soc. Mass Spectrom. 22: 1501-1507, 2011.

83) P. Vreken, A. E. van Lint, A. H. Bootsma, H. Overmars, R. J. Wanders, A. H. van Gennip. Quantitative plasma acylcarnitine analysis using electrospray tandem mass spectrometry for the diagnosis of organic acidaemias and fatty acid oxidation defects. J. Inherit. Metab. Dis. 22: 302-306, 1999.

84) M. S. Rashed, M. P. Bucknall, D. Little, A. Awad, M. Jacob, M. Alamoudi, M. Alwattar, P. T. Ozand. Screening blood spots for inborn errors of metabolism by electrospray tandem mass spectrometry with a microplate batch process and a computer algorithm for automated flagging of abnormal profiles. Clin. Chem. 43: 1129-1141, 1997.

85) E. H. Smith, D. Matern. Acylcarnitine analysis by tandem mass spectrometry. Curr. Protoc. Hum. Genet. 64: 17.8.1-17.8.20, 2010.

86) H. Chen, A. Venter, R. G. Cooks. Extractive electrospray ionization for direct analysis of undiluted urine, milk and other complex mixtures without sample preparation. Chem. Commun. (Camb.) 19: 2042-2044, 2006

87) H. Chen, S. Yang, A. Wortmann, R. Zenobi. Neutral desorption sampling of living objects for rapid analysis by extractive electrospray ionization mass spectrometry. Angew. Chem. Int. Ed. Engl. 46: 7591-7594, 2007.

88) M. Li, J. Ding, H. Gu, Y. Zhang, S. Pan, N. Xu, H. Chen, H. Li. Facilitated diffusion of acetonitrile revealed by quantitative breath analysis using extractive electrospray ionization mass spectrometry. Sci. Rep. 3: 1205, 2013.

89) J. Shiea, M. Z. Huang, H. J. Hsu, C. Y. Lee, C. H. Yuan, I. Beech, J. Sunner. Electrospray-assisted laser desorption/ionization mass spectrometry for direct ambient analysis of solids. Rapid Commun. Mass Spectrom. 19: 3701-3704, 2005.

90) P. Nemes, A. Vertes. Laser ablation electrospray ionization for atmospheric pressure, in vivo, and imaging mass spectrometry. Anal. Chem. 79: 8098-8106, 2007.

91) H. Li, P. Balan, A. Vertes. Molecular imaging of growth, metabolism, and antibiotic inhibition in bacterial colonies by laser ablation electrospray ionization mass spectrometry. Angew. Chem. Int. Ed. Engl. 55: 15035-15039, 2016.

92) C. W. Lee, H. Su, P. Y. Chen, S. J. Lin, J. Shiea, S. J. Shin, B. H. Chen. Rapid identification of pesticides in human oral fluid for emergency management by thermal desorption electrospray ionization/mass spectrometry. J. Mass Spectrom. 51: 97-104, 2016.

93) C. Shiea, Y. L. Huang, D. L. Liu, C. C. Chou, J. H. Chou, P. Y. Chen, J. Shiea, M. Z. Huang. Rapid screening of residual pesticides on fruits and vegetables using thermal desorption electrospray ionization mass spectrometry. Rapid Commun. Mass Spectrom. 29: 163-170, 2015.

94) C. W. Lee, H. Su, K. D. Wu, J. Shiea, D. C. Wu, B. H. Chen, S. J. Shin. Rapid point-of-care identification of oral medications in gastric lavage content by ambient mass spectrometry in the emergency room. Rapid Commun. Mass Spectrom. 30: 1295 1303, 2016.

95) C. L. Feider, N. Elizondo, L. S. Eberlin. Ambient ionization and FAIMS mass spectrometry for enhanced imaging of multiply charged molecular ions in biological tissues. Anal. Chem. 88: 11533-11541, 2016.

96) R. L. Griffiths, A. J. Creese, A. M. Race, J. Bunch, H. J. Cooper. LESA FAIMS Mass spectrometry for the spatial profiling of proteins from tissue. Anal. Chem. 88: 6758-6766, 2016.

97) L. Li, T. C. Chen, Y. Ren, P. I. Hendricks, R. G. Cooks, Z. Ouyang. Mini 12, miniature mass spectrometer for clinical and other applications-Introduction and characterization. Anal. Chem. 86: 2909-2916, 2014.

98) J. M. Perkel. Miniaturizing mass spectrometry. Science: 928 930, 2014. (DOI: 10.1126/science.opms.p1400082)

99) K. E. Blick. Current trends in automation of immunoassays. J. Clin. Ligand Assay 22: 6-12, 1999.

100) P. St-Louis. Status of point-of-care testing: Promise, realities, and possibilities. Clin. Biochem. 33: 427-440, 2000. 